Шушарина Г. А., Матвеев Н. А.

G. A. Shusharina, N. A. Matveyev

РЕЧЕВОЙ ЖАНР «ПРИЗНАНИЕ» КАК ЖАНР УСТНОЙ РЕЧИ

\title{
SPEECH GENRE «CONFESSION» AS A GENRE OF ORAL SPEECH
}

Шушарина Галина Алексеевна - кандидат филологических наук, заведующий кафедрой лингвистики и межкультурной коммуникации Комсомольского-на-Амуре государственного технического университета (Россия, г. Комсомольск-на-Амуре); 681013, г. Комсомольск-на-Амуре, пр. Ленина, д. 27. E-mail: lmk@knastu.ru.

Ms. Galina A. Shusharina - PhD in Philology, Head of the Department of Linguistics and Cross-Cultural Communication, Komsomolsk-on-Amur State Technical University (Russia, Komsomolsk-on-Amur), Komsomolsk-onAmur, 27, Lenina Str. E-mail: 1mk@knastu.ru.

Матвеев Никита Алексеевич - магистрант кафедры лингвистики и межкультурной коммуникации Комсомольского-на-Амуре государственного технического университета (Россия, г. Комсомольск-на-Амуре); 681013, г. Комсомольск-на-Амуре, пр. Ленина, д. 27. E-mail: sirius2804@mail.ru.

Mr. Nikita A. Matveyev - Master's Degree student, Department of Linguistics and Cross-Cultural Communication, Komsomolsk-on-Amur State Technical University (Russia, Komsomolsk-on-Amur), Komsomolsk-on-Amur, 27, Lenina Str. E-mail: sirius2804@mail.ru.

Аннотация. В статье рассматриваются параметры речевого жанра «признание» как одного из жанра устной речи. Анализ параметров происходит в связке с анализом жанровой модели речевого жанра «признание».

Summary. This article discusses the parameters of the speech genre as a genre of oral speech. The analysis takes place in conjunction with the analysis of the genre model of the speech genre «confession».

Ключевые слова: речевой жанр, признание, модель речевого жанра.

Key words: speech genre, confession, speech genre model.

\section{УДК 81.42}

Теория речевых жанров сегодня приобретает все большую популярность, несмотря на то что, история ее развития насчитывает несколько десятков лет. Исследователи неоднократно предлагали различные классификации речевых жанров, например Арутюнова, Т.В. Шмелева, В.В. Дементьев и т.д. При этом, по мнению В.В. Дементьева, «более жизнеспособными и востребованными оказывались не детально разработанные, завершенные классификации, а отдельные типологические идеи» $[1,95]$. Кроме того, лингвисты предлагают различные модели речевых жанров. В своем исследовании мы опираемся на модель, предложенную Т.В. Шмелевой, которая предполагает определение и описание коммуникативной цели, образа автора, образа адресата (слушающего), образа прошлого, образа будущего (последующий эпизод коммуникации, дальнейшее развитие речевых событий), диктумного (событийного) содержания и параметров языкового воплощения [4].

Речевой жанр «признание» - один из самых древних жанров, который сохранился до настоящего времени. За долгую историю существования сформировались основные жанровые признаки, разновидности, композиция. Согласно словарю С.И. Ожегова, признание - это: 1) открытое и откровенное сообщение о своих действиях, поступках; 2) объяснение в любви; 3) оценка по достоинству, положительное отношение со стороны кого-чего-н. [3].

Речевой жанр «признание» является одним из жанров устной формы речи, в связи с чем включает в себя такие жанрообразующие признаки, как понимание звучащей речи, осуществление 
новых речевых высказываний, непосредственный либо опосредованный техническими средствами контакт собеседников и постоянная обусловленность речевой ситуацией.

Например, в фильме «Звездные воины: Империя наносит ответный удар» (1980) создается ситуация, при которой единственно возможным вариантом коммуникативного взаимодействия является устная форма: установлен непосредственный контакт между коммуникантами - принцесса Лея и Хан стоят перед друг другом, а коммуникативная ситуация напряжения (диктумное содержание) и предвидения неминуемой смерти адресата сообщения и невозможности донести сообщение в будущем (образ будущего) вынуждает автора высказывания начать коммуникацию: Leia: I love you. Han: I know. Высказывание принцессы Леи является «признанием в любви», которое состоит из: 1) императивной коммуникативной цели - «хочу», чтобы ты знал о моих чувствах и что-то сделал», 2) образа автора - принцесса Лея, 3) образа адресата - Хан и имперские офицеры, 4) образа прошлого - героические события до попадания в плен, 5) образ будущего - смерть адресанта сообщения и невозможность получить это сообщение в будущем, 6) событийное содержание - плен, 7) композиция высказывания - субъект + предикат + объект, 8) код - язык, невербальные средства общения (жесты и мимика).

В мультипликационном фильме «Красавица и чудовище» (1991) также присутствует жанр «признание», обусловленный речевой ситуацией: Belle: Please, don't leave me. I love you. В данном примере прослеживаются следующие параметры: коммуникативная цель - императивная - желание Бэль вызвать осуществление желаемых ею событий; образ автора - девушка, нежелающая потерять возлюбленного; образ адресанта - умирающее Чудовище; образ прошлого - погоня за чудовищем и последний упавший лист розы; образ будущего - положительная ответная реакция: снятие проклятия и долгая счастливая жизнь вместе; событийное содержание - Бэль находится в отчаянии, плачет, целует возлюбленного; композиция высказывания - субъект + предикат + объект; код - язык и невербальные средства общения (жесты, мимика, поза).

Стоит отметить, что в вышеуказанных примерах устная речь была спонтанной, неподготовленной.

Второй характерной чертой устной речи и, соответственно, жанра «признание», поскольку он формируется преимущественно в устной речи, является монологичность.

Монолог - развернутое высказывание одного лица, которое обращено к одному либо нескольким адресатам. По цели высказывания монологическую речь делят на три основных типа: информационный, убеждающий и побуждающий.

Информационная речь служит для передачи знаний. В этом случае говорящий должен, прежде всего, учитывать как интеллектуальные способности восприятия информации слушателями, так и познавательные возможности.

Убеждающая речь обращена, прежде всего, к эмоциям слушателя. В этом случае говорящий должен учитывать его восприимчивость. ствиям [2].

Побуждающая речь направлена на то, чтобы побудить слушателей к различного рода дей-

Монологическим высказыванием называется такой отрезок речи, который находится между двумя соседними высказываниями и обладает определенными параметрами. Любое монологическое высказывание диалогично по своей природе, всегда кому-то адресовано, даже если этот адресат - сам говорящий, хотя в структурном и многих других отношениях его виды весьма специфичны [2].

Рассмотрим особенности построения монологического высказывания и его характеристики на примере признания из кинофильма «В погоне за Эмми» (1996):

Alyssa Jones: Why are we stopping?

Holden McNeil: Because I can't take this.

Alyssa: Can't take what?

Holden: I love you.

Alyssa: You love me? 
Holden: I love you. And not in a friendly way, although I think we're great friends. And not in a misplaced affection, puppy-dog way, although I'm sure that's what you'll call it. And it's not because you're unattainable. I love you. Very simple, very truly. You're the epitome of every attribute and quality I've ever looked for in another person. I know you think of me as just a friend, and crossing that line is the furthest thing from an option you'd ever consider. But I had to say it. I can't take this anymore. I can't stand next to you without wanting to hold you. I can't look into your eyes without feeling that longing you only read about in trashy romance novels. I can't talk to you without wanting to express my love for everything you are. I know this will probably queer our friendship -no pun intended-but I had to say it, because I've never felt this before, and I like who I am because of it. And if bringing it to light means we can't hang out anymore, then that hurts me. But I couldn't allow another day to go by without getting it out there, regardless of the outcome, which by the look on your face is to be the inevitable shoot-down. And I'll accept that. But I know some part of you is hesitating for a moment, and if there is a moment of hesitation, that means you feel something too. All I ask is that you not dismiss that -at least for ten seconds-and try to dwell in it. Alyssa, there isn't another soul on this planet who's ever made me half the person I am when I'm with you, and I would risk this friendship for the chance to take it to the next plateau. Because it's there between you and me. You can't deny that. And even if we never speak again after tonight, please know that I'm forever changed because of who you are and what you've meant to me, which -while I do appreciate it- I'd never need a painting of birds bought at a diner to remind me of. (Alyssa opens the door and exits the car)

Holden: (sighs and then to himself) Was it something I said?

В данном примере в машине осуществляется диалог между молодым, влюбленным художником и девушкой. Через некоторое время Адам останавливает машину, для того чтобы признаться девушке в любви. Предшествующий жанр «беседа», выраженный в форме диалога, трансформируется в монолог, целью которого является побуждение к действию со стороны молодой женщины. Для достижения этой цели в монологе присутствуют эмоционально окрашенные лексические средства, связанные в одно семантическое поле со словом «любовь»-affection, unattainable, just a friend, лексические единицы, усиливающие значимость партнера - epitome, метафоры - next plateau. В данном монологическом высказывании присутствует также типичное для большинства любовных признаний выражение: I love уои. Для выражения образа прошлого автор монолога использует перфектную форму прошедшего времени: I've ever looked for, I've never fel. В качестве маркеров устной речи присутствуют частые повторы - very, I can't, And, anymore, сокращенные формы - you'd, can't, I'm, couldn't. Выражение «I can't take this anymore» подчеркивает критичность ситуации и зависимость высказывания от неё.

По модели Т.В. Шмелевой, высказывание Адама состоит из: 1) императивно-побуждающей коммуникативной цели - «I love you... not in a friendly way», 2) образа автора - возлюбленный Адам, 3) образа адресата - девушка, нежелающая отвечать на любовь Адама, 4) образа прошлого дружба между коммуникантами, 5) образа будущего - положительная либо негативная (this will probably queer) ответная реакция согласия со стороны Эммы, 6) событийного содержания - гроза, машина, только адресат и адресант, 7) композиции высказывания - текстовое многокомплектное высказывание, в котором присутствует компонент признания в любви, выстраиваемый по модели «субъект + предикат + объект», 8) кода - язык, невербальные средства общения (жесты и мимика). Кроме того, режиссер фильма использует знак-признак - гром - в момент начала функционирования жанра «признания», тем самым сообщая о провале коммуникативного воздействия.

Несомненно, главная задача любого высказывания - это передача некоторого сообщения, донесение новой, в нашем случае, неизвестной ранее информации до адресата, которая раскрывается в момент эмоционального и психологического напряжения автора сообщения - инициатора коммуникации. Поэтому третьей особенностью жанра «признание» является сообщение - тайна.

Рассмотрим признание Салли из фильма «Когда Гарри встретил Салли» (1989):

Sally: I love that you get cold when it's 71 degrees out. I love that it takes you an hour and a half to order a sandwich. I love that you get a little crinkle above your nose when you're looking at me like I'm nuts. I love that after I spend the day with you, I can still smell your perfume on my clothes. And I love 
that you are the last person I want to talk to before I go to sleep at night. And it's not because I'm lonely, and it's not because it's New Year's Eve. I came here tonight because when you realize you want to spend the rest of your life with somebody, you want the rest of your life to start as soon as possible.

В данном монологическом высказывании прослеживаются те же характерные жанровые признаки «признания», что и в вышеописанных. Однако стоит добавить, что коммуникативная цель, которую преследует автор высказывания, заключается в эффекте воздействия на эмоциональное состояние девушки. Образ автора - мужчина. Образ адресанта - девушка. Образ прошлого - помощь в поиске любимого. Образ будущего - положительная ответная реакция: поцелуй и долгая счастливая жизнь вместе. Событийное содержание - дискотека. Композиция высказывания - многокомпонентное высказывание, в котором присутствует компонент признания в любви - I love ..., выстраиваемый по модели «субъект + предикат + описание качества объекта». Код - язык и невербальные средства общения (жесты, мимика, повышение уровня голоса).

Еще одним существенным признаком речевого жанра «признание» является отсутствие обращения к адресату. Однако номинация адресата присутствует и выражается с помощью личных местоимений в объектном падеже и экспрессивных лексических единиц.

Таким образом, были выявлены повторяющиеся признаки в большинстве коммуникативных ситуациях, связанных с речевым жанром «признание»: коммуникативная цель - императивная, образ автора - мужчина, образ адресанта - женщина, образ будущего - положительная ответная реакция, композиция высказывания - комплексная с компонентом признания в любви «субъект + предикат + объект», код - язык и невербальные средства общения.

\section{ЛИТЕРАТУРА}

1. Дементьев, В. В. Жанрово-ролевые сценки: обоснование подхода к созданию энциклопедии речевых жанров / В. В. Дементьев // Жанры и типы текста в научном и медийном дискурсе: межвуз. сб. науч. тр. Вып. 6. - Орел: ОГИИК, ООО ПФ «Оперативная полиграфия», 2008. - С. 95-108.

2. Монолог [Электронный ресурс]. - Режим доступа: http.: // http://www.bibliotekar.ru/russkiy-yazyk/22.htm (дата обращения 30.11 .16 г.).

3. Ожегов, С. И. Толковый словарь русского языка: 80000 слов и фразеологических выражений С. И. Ожегов, Н. Ю. Шведова. - М.: ООО «А ТЕМП», 2006. - 944 с.

4. Шмелева, Т. В. Модель речевого жанра / Т. В. Шмелева [электронный ресурс]. - Режим доступа: http.: // http://www.sgu.ru/node/75212 (дата обращения 30.11.2016 г.). 